\title{
RAINWATER DISPERSAL OF BOTRYOSPHAERIA CONIDIA FROM INFECTED GRAPEVINES
}

\author{
N.T. AMPONSAH, E.E. JONES, H.J. RIDGWAY and M.V. JASPERS \\ Department of Ecology, Faculty of Agriculture and Life Science, P.O. Box 84, \\ Lincoln University, New Zealand
}

Corresponding author: Nicholas.Amponsah@lincoln.ac.nz

\begin{abstract}
Dispersal of spores was investigated for the Botryosphaeria species that are responsible for dieback in grapevines. Trapping for spores was carried out in a Canterbury vineyard during May 2008-April 2009 to investigate spore availability during the year. No spores characteristic of the Botryosphaeriaceae were collected on Vaseline ${ }^{\circledR}$-coated slides, which were considered suitable for wind dispersed spores, although spores of other fungi were collected. However, traps that collected rainwater runoff yielded conidia of the Botryosphaeriaceae. In haemocytometer counts of spores they were initially identified by morphology, and subsequently confirmed by PCR of rDNA followed by DNA sequencing. During the trapping period, $59.8 \%$ of the total Botryosphaeriaceae caught were Neofusicoccum spp. and $40.2 \%$ were Diplodia spp. These were present throughout the entire year, with most abundant conidia being detected during December, January and February, when summer temperatures were high and when routine trimming of mature canes provided the wounds needed for infection. Keywords: Botryosphaeriaceae, Botryosphaeria dieback, Neofusicoccum, Diplodia, grape, conidia.
\end{abstract}

\section{INTRODUCTION}

Species of Botryosphaeria (whose anamorphs are Neofusicoccum and Diplodia spp.) are major pathogens of grapevines worldwide (Taylor et al. 2005). They are cosmopolitan and can be saprophytes or endophytes on a wide range of woody angiosperm and gymnosperm hosts (Denman et al. 2000). Wind, rain-splash, insect feeding and contaminated pruning tools can contribute to dispersal of spores, which then infect grapevines through wounds (Epstein et al. 2008). Spore dispersal of three species of Botryosphaeria from peach prunings and diseased branches was investigated by Pusey (1989) using a Burkard spore trap for airborne ascospores and rainwater traps for conidia and ascospores. This research detected ascospores and conidia in rainwater runoff throughout most of the year, indicating the importance of $B$. dothidea conidia in rainwater and wind-blown rain for dispersal amongst peach trees.

The present study aimed to determine the seasonal prevalence in Canterbury, New Zealand, of Botryosphaeria species conidia dispersed from grapevines.

\section{Seasonal production of conidia}

\section{MATERIAL AND METHODS}

Trapping of conidia and ascospores of Botryosphaeria species was attempted in a 12-year-old 'Pinot noir' vineyard in Canterbury, where previous tissue sampling had yielded isolates identified by PCR of rDNA followed by DNA sequencing as Neofusicoccum luteum, N. australe, $N$. parvum and Diplodia mutila. These species had collectively infected trunks (47\%), canes (21\%), green shoots (11\%), plant debris $(11 \%)$, buds (5\%), leaves (3\%) and flowers (2\%) (Amponsah et al. 2007). Spore-trapping was carried out during May 2008 to April 2009. Green shoots that died back after summer 
trimming were used for fungal isolation as described by Amponsah et al (2007). Canes pruned off in winter were washed in water and the washings were centrifuged, so that any characteristic conidia in the pellet could be observed under a light microscope.

\section{Airborne dispersal}

To determine the possibility of wind dispersal under periods of little or no rain, microscope slides coated with Vaseline ${ }^{\circledR}$ were fixed using fold-back stationery clips onto wooden posts within the grapevine canopy at a height of $50 \mathrm{~cm}$. The 10 randomly selected posts each had a horizontal and a vertical slide. During July 2008 - February 2009 the slides were collected and replaced weekly, being inspected with a light microscope for characteristic Botryosphaeria conidia or ascospores, distinguished by their morphology and colour (Pennycook \& Samuels 1985; Philips 2002). The Vaseline ${ }^{\circledR}$ was then washed off the slides with $10 \mathrm{ml}$ of $30^{\circ} \mathrm{C}$ water and $100 \mu$ aliquots of each solution were plated onto three replicate plates of potato dextrose agar (PDA; Oxoid) amended with chloramphenicol $\left(0.1 \mu \mathrm{g} / \mathrm{ml}\right.$; Sigma-Aldrich Inc). After incubation in darkness at $24.5^{\circ} \mathrm{C}$ for 3-7 days, they were observed for characteristic colonies.

\section{Waterborne dispersal}

The rainwater runoff traps consisted of $210 \times 297 \mathrm{~mm}$ transparent acetate sheets folded and stapled at one end to create funnels whilst the opposite ends were stapled directly onto the middle portions of two opposing, wrapped-down canes (Fig. 1a). Each funnel base was placed into a $500 \mathrm{ml}$ container fixed at $20 \mathrm{~cm}$ above the ground. The 10 traps were attached to 10 randomly selected grapevines. After every significant rainfall event, the water was collected and the trap replaced. The collected water was then filtered through a $50 \mu \mathrm{m}$ mesh sieve lined with a double layer of cheese cloth. The filtrate was centrifuged at $2952 \times \mathrm{g}$ for $15 \mathrm{~min}$, the supernatant discarded and the pellet resuspended in $20 \mathrm{ml}$ sterile distilled water. Spores in these suspensions, which were characteristic of Diplodia spp. and Neofusicoccum spp., were counted with a haemocytometer. Aliquots $(100 \mu \mathrm{l})$ of a dilution $\left(10^{4} / \mathrm{ml}\right)$ of the spore suspensions were also plated out and colonies identified as above. The total remaining spores from two spore harvests per month were used for molecular identification using PCR of the rDNA followed by DNA sequencing, to confirm the presence of species belonging to the genus Botryosphaeria, using similar methods to Alves et al. (2005).

\section{Statistical analysis and weather data}

The total conidia per month were $\log _{10}(x+1)$ transformed and data analysed by a regression suitable for an unbalanced design using GenStat version 11, with means being separated by least significant differences. Total rainfall and means of maximum daily temperature and relative humidity for each month are shown in Figs $2 \mathrm{a} \& 2 \mathrm{~b}$. These data were collected at the Templeton station, which is about $6 \mathrm{~km}$ away from the vineyard, and accessed from the National Institute of Water and Atmospheric Research, New Zealand (http//www.niwa.co.nz/ncc/data).

\section{RESULTS}

Although many spores were trapped on Vaseline ${ }^{\circledR}$-coated slides, none were characteristic of the ascospores or conidia of Neofusicoccum and Diplodia spp. and plating of the spores on agar produced no colonies characteristic of these species. In contrast, the rainwater traps caught conidia of these species (arrows in Fig. 1b) and those of other fungal species. Spore suspension plated on PDA and incubated at $25^{\circ} \mathrm{C}$ also grew colonies characteristics of Botryosphaeria spp. The proportion of spores collected in 10 traps during the year was $59.8 \%$ that were characteristic of Neofusicoccum spp. and $40.2 \%$ for Diplodia spp.

Mean numbers of Neofusicoccum spp. conidia trapped differed significantly between months $(\mathrm{P}=0.001)$. Numbers were highest in summer months, especially January and February, but were significantly lowest in March and April (Fig. 2c). There was a decrease in conidium numbers after June, when the winter pruning reduced the wood in the canopy from more than 10 canes to 2 canes. Washings of the canes collected from the vineyard floor had abundant Botryosphaeria spp. conidia (data not shown). 

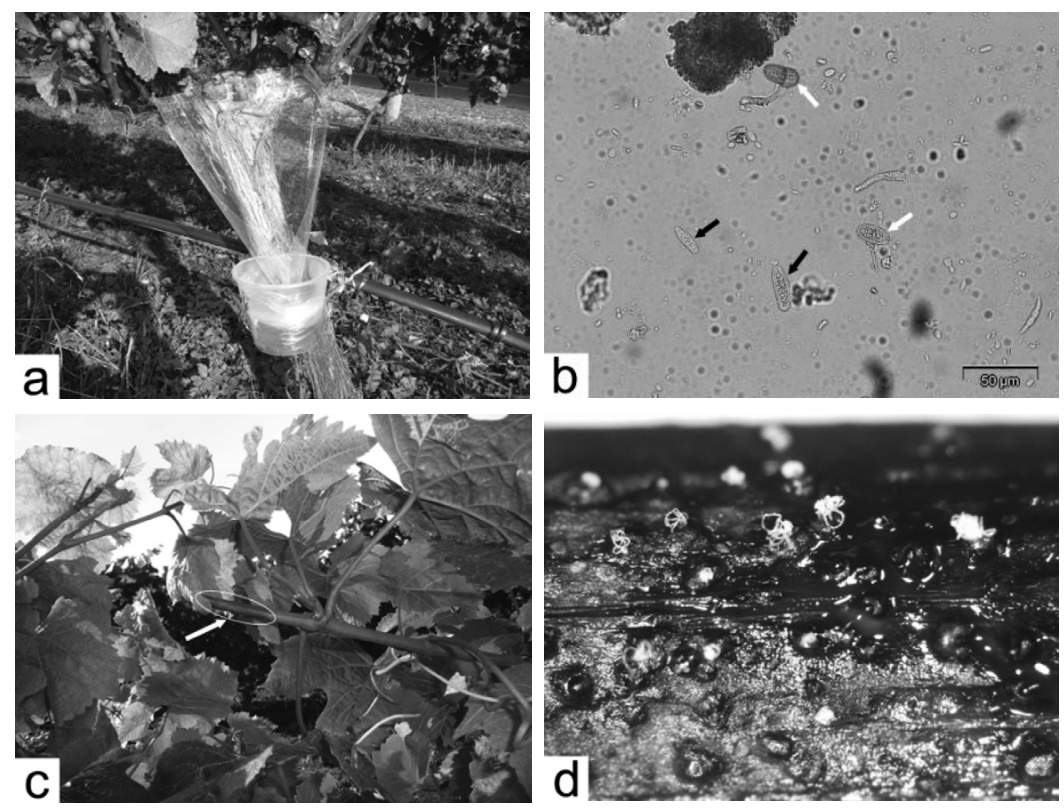

FIGURE 1: (a) Rainwater trapping setup fixed on to a grapevine trunk. (b) Light microscope view of Neofusicoccum spp. conidia indicated by black arrows and Diplodia spp. indicated by white arrows, which were present in a rainwater sample. (c) Shoot showing Botryosphaeria dieback after summer pruning (February 2009) in the Canterbury vineyard where the conidium trapping experiment was carried out. (d) Grapevine tissue from a Canterbury vineyard (March 2009) showing pycnidia oozing conidia in paste tendrils.

Mean numbers of Diplodia spp. conidia trapped differed significantly between months $(\mathrm{P}=0.001)$. Numbers were highest in summer months, especially January, but were also relatively high in April and May. The lowest numbers of Diplodia conidia were trapped in November, which coincided with the lowest monthly rainfall (Fig. 2c). Overall, the monthly conidium counts of both these genera did not appear to be directly related to monthly rainfall or mean monthly relative humidity (Fig. 2c), or by the periodicity of rainfall (data not shown).

Sequencing of the PCR products from the conidia confirmed them as Neofusicoccum and Diplodia species. The green shoots with dieback symptoms (Fig. 1c), that were incubated under high humidity, produced pycnidia that oozed conidia similar to those of the Neofusicoccum and Diplodia species in rainwater traps (Fig. 1d). 

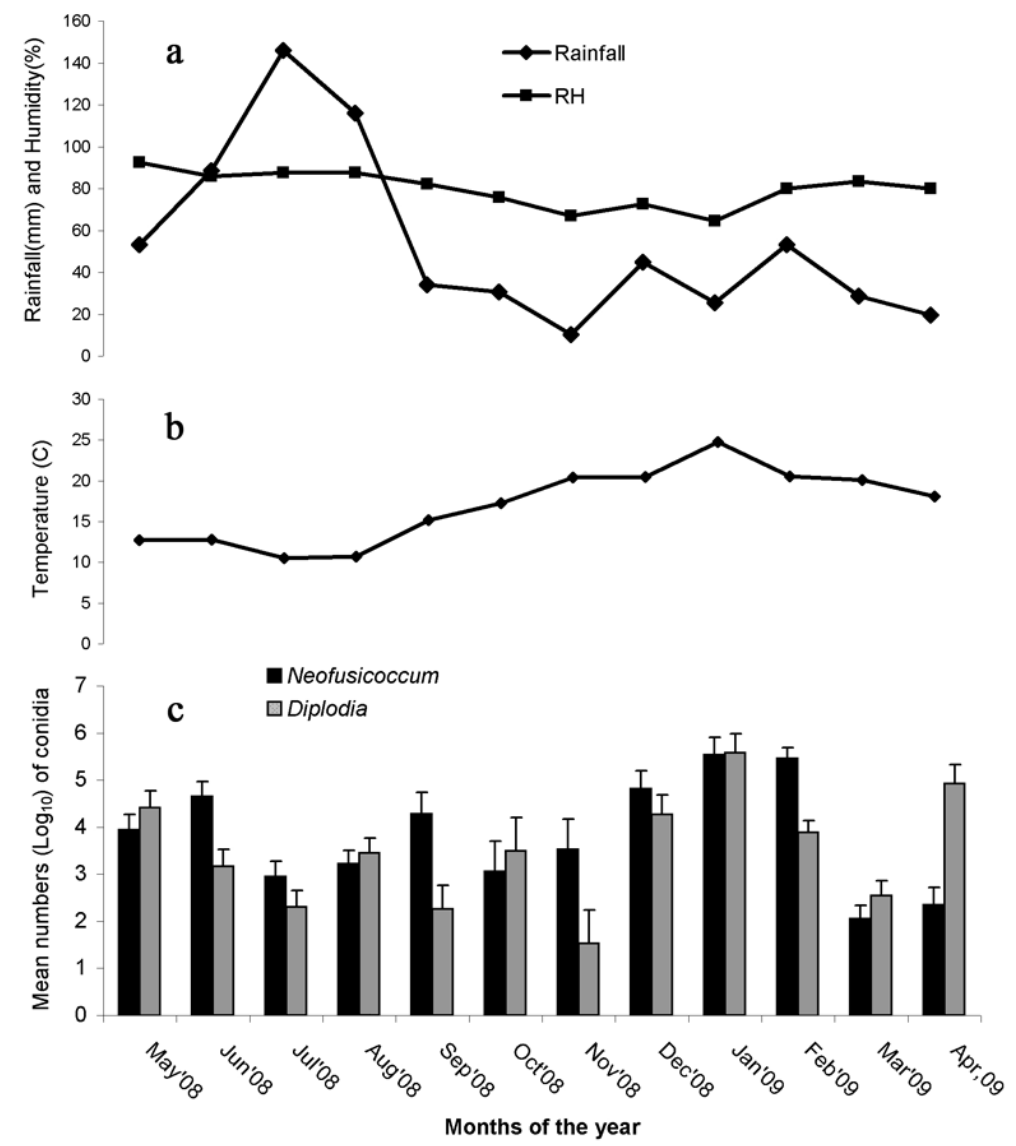

FIGURE 2: (a) Total monthly rainfall $(\mathrm{mm})$ and mean relative humidity $(\%)$ for the duration of the sampling period. (b) Mean of daily maximum temperatures $\left({ }^{\circ} \mathrm{C}\right.$ ) for each month during the sampling period. (c) Mean numbers $\left(\log _{10}\right)$ of conidia characteristic of Neofusicoccum spp. and Diplodia spp. collected each month in 10 water traps within a Canterbury grape canopy during May 2008 to April 2009. Bars represent standard errors of the monthly mean conidium numbers.

\section{DISCUSSION}

This study has shown that conidia of the Botryosphaeriaceae, such as Neofusicoccum and Diplodia spp., were present throughout the year in a Canterbury vineyard in rainwater run-off. Overall, the numbers of conidia increased from late spring through to summer with lower numbers in winter and early spring. This concurs with reports by Pusey (1989) and Sutton (1981) who found that waterborne conidia of B. dothidea and B. obtusa were abundant in the air of peach and apple orchards, respectively, during rainy periods and that the amount and duration of rainfall were the most important factors in 
waterborne dispersal of ascospores and conidia. In the present study, the numbers of conidia trapped in rainwater, and the observation that infected canes incubated under high humidity oozed conidia from pycnidia in a water soluble paste (Fig. 1d), indicate that rainfall provides the mechanism for conidium dispersal.

The failure of the Vaseline ${ }^{\circledR}$-coated slides to capture airborne ascospores characteristic of the Botryosphaeriaceae led to the termination of this trapping method after 32 weeks. Since no perithecia were observed on any of the diseased grapevine tissue collected during an earlier sampling (Amponsah et al. 2007), this seemed to indicate that airborne ascospores were not present in the vineyard, only conidia. In contrast to this study, Pusey (1989) observed the release of ascospores of B. obtusa and B. rhodina during periods of wetness and of $B$. dothidea soon after periods of wetness. This observation, however, differed from those of Sutton (1981), who observed that ascospores of $B$. dothidea were usually more abundant at the beginning of a rain period. Both studies used a Burkard volumetric spore trap, which may have been more effective than the Vaseline ${ }^{\circledR}$-coated slides used in this study.

Greater numbers of conidia were trapped during periods of high temperature, a finding that concurs with a report by Pusey (1989) who detected waterborne conidia of $B$. dothidea for most of the year, but not in winter (January and February in North America), and airborne ascospores of B. dothidea, B. obtusa and B. rhodina in April (spring in North America). In the present study, the numbers of Botryosphaeriaceae conidia were generally lower in July through to November and also low in March (Fig. 2c). However, the larger numbers of conidia trapped in June before pruning were probably washed from the numerous canes on the vines, since there was a reduction in conidium numbers in July after pruning. This finding was verified by washing dropped, pruned canes, which yielded solutions containing high concentrations of conidia for both Neofusicoccum and Diplodia spp. (data not shown).

The abundance of conidia from December to February was probably related to the rise in temperature as well as there being a large canopy of mature canes at that time. Britton $\&$ Hendrix (1986) reported that conidia and ascospores of $B$. dothidea predominated in summer and autumn whilst those of $B$. obtusa predominated in spring. Copes \& Hendrix (2004) also observed that Botryosphaeria species were able to produce conidia over a wide temperature range of $6-30^{\circ} \mathrm{C}$, with optimum production occurring around $18-24^{\circ} \mathrm{C}$. This explains why conidia were present throughout the year in Canterbury, including winter periods. Since conidia were only trapped in rainwater run-off, this indicates the role of rain in conidium release and dispersal in New Zealand vineyards. This has significant implications for potential infection of grapevines during pruning or trimming operations, indicating the need to apply pruning wound treatment irrespective of season.

\section{ACKNOWLEDGEMENT}

The authors wish to thank the New Zealand Winegrowers association for funding this project and also the vineyard owner who allowed sampling and spore trapping from his vineyard.

\section{REFERENCES}

Amponsah NT, Jones EE, Ridgway HJ, Jaspers MV 2007. Distribution, identification and inoculum sources of Botryosphaeria species found in New Zealand vineyards. Proceedings of the 16th Biennial Australasian Plant Pathology Society Conference, Adelaide. p. 58 (Abstract only).

Alves A, Phillips AJL, Henriques I, Correia A 2005. Evaluation of amplified ribosomal DNA restriction analysis as a method for the identification of Botryosphaeria species. FEMS Microbiology Letters 245(2): 221-229.

Britton KO, Hendrix FF 1986. Population dynamics of Botryosphaeria spp. in peach gummosis cankers. Plant Disease 70: 134-136.

Copes WE, Hendrix FF 2004. Effect of temperature on sporulation of Botryosphaeria dothidea, B. obtusa, and B. rhodina. Plant Disease 88(3): 292-296. 
Denman S, Crous PW, Taylor JE, Kang J-C, Pascoe I, Wingfield MJ 2000. An overview of the taxonomic history of Botryosphaeria, and a re-isolation of its anamorphs based on morphology and ITS rDNA phylogeny. Studies in Mycology 43: 129-140.

Epstein L, Kaur S, VanderGheynst JS 2008. Botryosphaeria-related dieback and control investigated in non coastal California grapevines. California Agriculture 62(4): 161-166

Pennycook, SR, Samuels GJ 1985. Botryosphaeria and Fusicoccum species associated with ripe fruit rot of Actinidia deliciosa (kiwifruit) in New Zealand. Mycotaxon 24:445-458.

Phillips AJL 2002. Botryosphaeria species associated with diseases of grapevines in Portugal. Phytopathology Mediterranean 41:3-18.

Pusey PL 1989. Availability and dispersal of ascospores and conidia of Botryosphaeria in peach orchards. Phytopathology 79: 635-639.

Sutton TB 1981. Production and dispersal of ascospores and conidia by Physalospora obtusa and Botryosphaeria dothidea in apple orchards. Phytopathology 71: 584-589.

Taylor A, Hardy GES, Wood P, Burgess T 2005. Identification and pathogenicity of Botryosphaeria species associated with grapevine decline in Western Australia. Australasian Plant Pathology 34(2): 187-195. 